\title{
Thermo physical Properties of a Sun Dried Clay Brick Moulded with Cement and Neem Leaves Ash as Additives
}

\author{
${ }^{1}$ Hamza, B and ${ }^{2}$ Abdulmuminu, I \\ ${ }^{1}$ Department of physics, \\ UsmanuDanfodiyo University \\ Sokoto -Nigeria \\ ${ }^{2}$ Department of physics \\ Federal University Gusau, \\ Zamfara-Nigeria
}

\begin{abstract}
Neem tree (Azadiractaindica) popularly known as "Dogonyaro" is very common in Nigeria, more especially in the northern part of the country. The problem of the neem leaves waste, make the leaves to be burnt into ashes, however burning the leaves does not solve the waste problem completely. The problem of waste disposal and the cost of cement in the brick moulded for building led to this study on the thermophysical properties of clay brick moulded with cement and neem leaves ash. The mixture of clay, cement and Neem leaves ash at varying proportion (100\% clay, 30\% cement, 5\%, 10\%, 15\% and 20\% Neem leaves ash) was loaded into a wood mould compartment, manually tamped, levelled, and also shade cured for 5, 13, 19, 26 and 33 days. The results showed that when Neem leaves ash content is $10 \%$ (20\% cement), the highest average compressive strength of $1.50 \mathrm{~N}^{-} \mathrm{mm}^{-}$ ${ }^{2}$ at 33 curing days was obtained, when Neem leaves ash content is also $10 \%$ (20\% cement) the highest modulus of the rapture of $0.71 \mathrm{~N} \mathrm{~mm}^{-2}$ at 12 curing days was obtained when Neem leaves ash content is $20 \%$ (10\% cement), the highest water absorption of $16.1 \%$ at 5 days of curing was obtained when Neem leaves ash content is $5 \%$ (25\% cement), the highest initial rate of absorption of $1.43 \mathrm{~kg} \mathrm{~m}^{-2} \mathrm{~min}^{-1}$ at 5 curing days was obtained, when $0 \%$ Neem leaves ash (30\% cement), the highest density of $2.843 \mathrm{~kg} \mathrm{~mm}^{-3}$ was obtained, also when Neem leaves content is $10 \%$ ( $20 \%$ cement) of $2 \mathrm{~cm}$ thickness, the highest thermal conductivity of 164.45 $\mathrm{wm}^{-1} \mathrm{k}^{-1}$ at 6 minutes of 26 days was obtained. This shows that Neem leaves ash as partial replacements of cement in clay bricks possess better reliability and workability in both the physical and thermal properties of clay bricks.
\end{abstract}

Key Words: Neem leaves, Cement, Clay, Brick, Thermal property, Physical Property.

\subsection{INTRODUCTION}

Clay brick is one of the first man made artificial building materials and one of the oldest building materials known. It widespread use is mainly due to the availability of clay in most countries. Its durability and aesthetic appeal also contribute to it extensive application of both loads bearing and non-load bearing structures. The properties of clay unit depend on the mineralogical composition of the clay used to manufacture the unit and the manufacturing process. (Ahmed et al, 2011).

Neem leaf ash is obtained by burning the waste leaves obtain from the tree. Neem leaf itself is from neem tree (Azadiractaindica) popularly known as "Dogonyaro".

Waste is a great concern among governmental agencies, and environmentalist regarding the increasing amount of waste throughout the world (Abdeen, 2016).

The cost of building materials especially walling materials in Nigeria is very high. This has made people to use other alternative materials like Bamboo, Stones, Clay product, and Wood which are dependable and not quite expensive to acquire (Jwasshaka, 2012). 
Sun-dried clay brick walls have the problem of cracking due to drying shrinkage, high rate of water absorption which leads to many houses collapsing during heavy rain fall, Rodents boring holes easily in the walls, low compressive, tensile and shear strength. These problems especially low compressive strength have made building with sun-dried clay bricks not strong, durable and have led to the collapse of many buildings especially during heavy rain, killing and maiming the occupants as well as loss of property. Because of these problems posed by the traditional method of utilizing clay bricks and with the increase in demand for housing, the traditional building system has not satisfied the need for adequate building materials and techniques for construction (Jwasshaka,2012). Hence, the challenge for the study to the thermal and physical properties of clay bricks with cement and Neem leaves ash.

\subsection{LITERATURE REVIEW}

The brick was historically manufactured by an ancient method dating back to 6000 B.C called the soft mud process in which relatively moist clay is pressed into simple rectangular moulds by hands. To keep the sticky clay from adhering to the moulds, the moulds may be dipped in water immediately before being filled, producing brick with a relatively smooth, dense, surface know as water struck brick. The bricks manufacturing was slightly developed from the sift mud process to the dry press process that was used for the clay that shrinks while drying. The ancient fired brick was manufactured by forming the mixed clay in molds and then bricks were fired by stacking them in a loose array called clamp covering the clamp with earth or clay, building a wood fire under the clamp and maintaining the fire for several days.(Mohammed and Shakir, 2013).

The compressive strengths of bricks vary considerably with the material used in manufacturing and the curing condition. Bricks compressive strengths can be defined into three levels i.e. the high strength engineering bricks with compressive strength ranging from 55 to $69 \mathrm{~N} / \mathrm{mm}^{2}$, the medium strength bricks range from 27 to $48 \mathrm{~N} / \mathrm{mm}^{2}$ and the low strength brick range from approximately 14 to $25 \mathrm{~N} / \mathrm{mm}^{2}$ (Lenczner,1972). Due to these considerable variations, strengths of bricks are classified accordingly to its application in construction. Bricks with compressive strengths of approximately $5 \mathrm{~N} / \mathrm{mm} 2$ are sufficient for the construction of low-rise buildings like dwelling houses (Hendry et al., 1981). For high-rise structures, engineering bricks and those of high compressive strengths should be used (Hendry, 2001). The compressive strengths of bricks were associated with materials and manufacturing features (Grimm (1975).

Water absorption of a brick is defined as the weight of water in a brick expressed as a percentage of the brick's dry weight. It varies roughly from 4.5 to $21 \%$ and the variation is mainly due to the variable raw material and the manufacturing process. The extrusion process in the manufacturing produces denser brick in comparisons to the molded bricks and denser bricks in turn would exhibit less absorption. This was proven through experiments (Sahlin, 1971), which showed that extruded bricks contain small percentage of voids and therefore are less absorbent to water.

The effects of bricks absorption property due to variable raw material used in its manufacturing was shown by Surej et al. (1998) who reported the work carried out by Kung (1987) on the effects of raw material to water absorption. The report showed that within the normal brick firing temperature range, the water absorption 20 and the porosity of the burnt bricks increases with increasing calcium carbonate or limestone content in the raw materials. Water absorption $W$, in percentage was calculated using the following equation. (2.1)

$W \%=100\left(\frac{M_{s}-M_{d}}{M_{d}}\right)$

Where $M_{d}$ is the dry mass and $M_{s}$ is the saturated mass

The initial rate of absorption (IRA) is the amount of water absorbed in one minute through the bed face of the brick. It is a measure of the brick's 'suction'.

The optimum value of IRA is considered to be between 0.5 and $1.5 \mathrm{~kg} / \mathrm{m}^{2} / \mathrm{min}$. (Zainab, 2005). However, IRAs can exceed these limits. The mortar's water retentively should be matched to the brick type where good bond strength is critical. The initial rate of absorption due to area of immersion (IRA) in $\mathrm{kg} / \mathrm{m}^{2}$ min is calculated using eqn (2.2).

$I R A=1000 \frac{M_{w}-M_{d}}{A}$

Where $M_{d}$ is the mass of the dry brick in grams, $\quad M_{w}$ is the mass of the wet bricks in grams

$A$ is the area of the immersed faced of the bricks in $\mathrm{mm}^{2}$ 
Raw materials and manufacturing process affects bricks density, which could vary between $1300 \mathrm{~kg} / \mathrm{m} 3$ to $2200 \mathrm{~kg} / \mathrm{m} 3$. The density of bricks influences the weight of walls and the variations in weight have implications on structural, acoustical and thermal design of the wall. Incorrect assumptions on wall weight can result in inaccurate dead loads and seismic loads, reduced factor of safety in shear walls and overestimate of acoustical transmission loss (Grimm, 1996).The volume is calculated using the dimension in equation $(2.3)$

Volume $\left(\mathrm{mm}^{3}\right)=L \times B \times H$

Where $L$ is the length, $B$ is the breath and $H$ is the height of the bricks all in $\mathrm{mm}$

The volume is then used to calculate the density $D$ using equation (2.4)

$\mathrm{D}=M / V$

Where $M$ is the mass of the bricks in grams

As mentioned earlier, thermal conductivity describes the ability of a material to conduct heat and its unit is $[\mathrm{J} / \mathrm{m}$. K]. High thermal conductivity allows the material to transmit heat quickly when subjected to a small temperature gradient. Since the goal is to create thermal insulation, we want thermal conductivity to be as low as possible. Thermal conductivity is associated with heat transfer through conduction, meaning through the collision of molecules (vibration, translation, rotation). Therefore, the higher the density of the material, the more conductive it is, so we want our material lighter. Thermal conductivity allows for the transfer of heat from a warm surface to a cooler one, therefore lowering the temperature of the surface that emits heat. The temperature of the surface is only lowered by a quantity that depends on its heat capacity. And this heat transfer allows low temperature to infiltrate the house. It is now imperative to define heat capacity. Specific heat capacity $\mathrm{Cp}$ is the increase in internal energy associated with a rise in temperature, in other words, the material's capacity to store heat. It can also be defined as the amount of heat per unit mass required to raise the temperature by one degree Celsius. Volumetric heat capacity $\rho c$ is the product of density and specific heat capacity (Alexandra and Alan, 2013).

Materials have different heat capacities because they have different ways of storing heat, as we said earlier, heat storage which is related to the quantity of heat flow can be under the form of vibration, translation or rotation of the molecules.

Since our goal is to thermally insulate our house from the cold, we need our energy efficient home to have a very low thermal conductivity. The thermal conductivity $K$ due to the change in temperature in $\mathrm{Wm}^{-1} \mathrm{k}^{-1}$ is given according to Fourier equation

$Q=K A \frac{d T}{d z}$

$k=\frac{Q d z}{A d T}$

Where $k$ is the thermal conductivity and it is an extremely important thermal property that we will be using intensively during this project. It describes the ability of a material to conduct heat. A is the total surface area and $\frac{d T}{d z}$ is the temperature gradient.

The additives are components that when mixed with mud, improve its physical properties and its performance. These physical properties are: compression strength, density, porosity, water absorption, depth of penetration, abrasion resistance and hardness. The common additives can be divided in to two categories: organic and inorganic materials.

The additives should be water resistant, not closed pores and capillaries, and they should have good penetration. They ought to increase the mechanical strength and abrasion resistance. They must be durable, easily applicable, cheap, and reversible and they should not be chemically hazardous.

Most of these additives are widely available, inexpensive or might be free. There are two sources of organic materials; a vegetable source, e.g., straw, palm leaves, and rice husks, and an animal source, e.g., animal hair and dung (Torraca, 1988). Inorganic additives include: sand, pozzolana, ashes, Portland cement, Hydraulic lime and Gypsum etc.

Cost reduction has remained elusive in construction industry because of strong attachment to conventional building materials. Today in most part of the world, improvement in earth building technology has made it begin to gain technical and social 
acceptance among the rich and the poor (Maini, 2002). Those who recognized the environmental social and economic cost of current ways of construction believed that earth building provides part of solution to the complex world wide problem of sustainable living (Kennedy, 2002). Apart from the issue of reducing unemployment and creating micro industries, the direct cost saving in construction is between 8 and 18per cent (Burrough, 2002 and Howe, 1992). Earth building is in every aspect collaborative and as such can form the hub of other self-help initiatives within communities providing both capital and methodology (Ifeka, 2004).

According to Robson in Burrough, (2002b) earth houses are economical to build and no other building material can match the relationship of earth building to the environment. Experience has shown that earth remains a viable material, owing to the costly increases in production of modern building materials. Aggarwal (1981), Doatet al (1991) stated that the appropriate use of earth construction produces cost effective and comfortable buildings.

Literature on the economic benefits of contemporary stabilized earth construction with additives like Neem leaves ash is scanty and no structured research is available. Clay soil has been and may continue to be the most widely used building material throughout most developing countries. It is cheap, available in abundance and simple to form into elements (Morris and Booysen, 2000).

\subsection{MATERIALS AND METHOD}

\subsection{Preparing The Raw Materials}

Materials used for this study includes; clay soil, ordinary Portland cement and Neem leaves ash The soil used in this study is red clay soil which is available in UsmanuDanfodiyo University, Sokoto. Cement Company of Northern Nigeria, Sokoto state Ordinary Portland cement was used in this study.

The Neem leaves ash used was obtained from Neem trees around Sokoto State Energy Research Center, Sokoto State. It was burned in opening air to produce Neem leaves ash.

\subsection{Experimental Procedures}

In order to obtain comparable result, six different groups of samples were prepared for the test depending on the curing time. The samples were prepared by partially replacing clay with various percentages of cement and various percentages of Neem leaves ash (Table 3.1).

Table 3.1: Mixture proportion of raw materials

\begin{tabular}{|c|c|c|c|}
\hline Sample & Clay (\%) & Cement $(\boldsymbol{\%})$ & Neem leaves ash (\%) \\
\hline A & 100 & 0 & 0 \\
\hline B & 70 & 30 & 0 \\
\hline C & 70 & 25 & 5 \\
\hline D & 70 & 20 & 10 \\
\hline E & 70 & 15 & 15 \\
\hline F & 70 & 10 & 20 \\
\hline
\end{tabular}

From Table 3.1, for other percentages of clay, cement and Neem leaves ash are thoroughly mixed in powdered form and in correct proportion. Therefore, for $70 \%$ clay, the clay is partially replaced with $25 \%$ cement and $5 \%$ Neem leaves ash etc. the raw materials were mixed for $5 \mathrm{~min}$ to get a uniform consistency. After dry mixing, water was splashed on the powered mixtures for the production of mould bricks samples.Each sample is formed using wood mold. Test specimen with a dimension $160 \mathrm{~mm}(\mathrm{H}) \times$ $40 \mathrm{~mm}(\mathrm{~W}) \times 40 \mathrm{~mm}(\mathrm{H})$ and $2 \mathrm{~cm} 1.5 \mathrm{~cm}$ and $1 \mathrm{~cm}$ thickness with diameter $10 \mathrm{~cm}$ of disked-liked specimen were molded. The mixed sample was poured into the mold hand tamped and leveled. The sample then was pulled out. The shaped samples were sundried. A total of 240 samples were prepared to testing from the mold and left several days until become dried. 


\subsection{Curing of the samples}

The different sets of bricks were sun dried for 5, 12, 19, 26 and 33 days in the open field because at each day the samples would have been practically strong enough for use. During the curing period, shade curing method was adopted. All bricks were shaded with Neem leaves to avoid spontaneous drying that would cause shrinkage and leads to cracks. The first laboratory test commences after 5 days of curing the specimen in an open field.

\subsection{Testing Program}

For testing program, five bricks samples for each curing time for the six group samples listed previously in Table 3.0. These five bricks samples are divided into five categories, one for compressive strength, one for modulus of rapture, one for initial rate of absorption and density and one for thermal conductivity.

\subsubsection{Physical Properties}

Several physical properties of sun-dried clay bricks can be determined: compressive strength, modulus of rapture, initial rate of absorption and water absorption.

\subsubsection{Compressive Strength}

The compressive strength was investigated by using the Universal compressive testing machine available in the Cement Company of Northern Nigeria laboratory. Six bricks from each level of Neem leaves ash addition at each curing time were tested and average compressive strength was calculated.

\subsubsection{Modulus of Rapture}

Modulus of rapture test was conducted in the factory laboratory at Cement Company of Northern Nigeria, Sokoto state. Universal testing machine was used to conduct the test. Bricks from each level of Neem leaves ash addition at each curing time were tested.

\subsubsection{Water Absorption}

Absorption test of much shorter duration was adopted. In this test, samples were weighed using weighing balance that can be readable up $0.001 \mathrm{~g}$. The dry mass $M_{d}$ was recorded.

A bucket was used to accommodate five set of samples. The bricks are arranged in two tiers with space in between bricks and tiers and allowed to stay foe $30 \pm 05 \mathrm{~min}$. After $30 \pm 05 \mathrm{~min}$, the samples are removed from the water. Each bricks are weighed and the saturated mass $M_{s}$, recorded.

\subsubsection{Initial Rate Of Absorption}

In this test, the bricks were weighed and the dry mass $M_{d}$ recorded using weighing balance. In the test a bucket of water was used. The pre-weighed dry bricks were immersed completely in the bucket of water for the duration of one minute. After one minute, the bricks was removed from the water and excess water wiped off with a damped cloth. The bricks were reweighed and the wet mass $M_{w}$ was recorded. These procedures were repeated for 6 bricks for each batch.

\subsubsection{Thermal Properties}

\subsubsection{Density}

In this test, the same samples used for initial rate of absorption were used first to test density before the initial rate of absorption. Each sample is weigh using balance scale and the mass $M$ is recorded. Meter rule is use to determine the dimension of the sample.

\subsubsection{Thermal Conductivity}

The thermal conductivity test on the samples produced using circular disk wood mold of thickness $2 \mathrm{~cm}$ and of diameter $10 \mathrm{~cm}$ were carried out. Each disks-liked bricks were placed on an electrical hot plate of voltage 250volts and current 16Amperes. A digital multi-thermometer is used to measure the heat flow between the both flat surface of the disk at specific time difference (2min, $4 \mathrm{~min}, 6 \mathrm{~min} 8 \mathrm{~min}$ ), neglecting heat lost. 


\subsection{RESULTS AND DISCUSSION}

\subsection{Results}

The following different laboratory tests were carried out on the samples to determine their performances. These tests include; Compressive strength, Modulus of rapture, Water absorption and initial rate of absorption in one hand and Density and thermal conductivity on the other hand.

\subsubsection{Average Compressive Strength}

These results were obtained for different samples after few curing days.

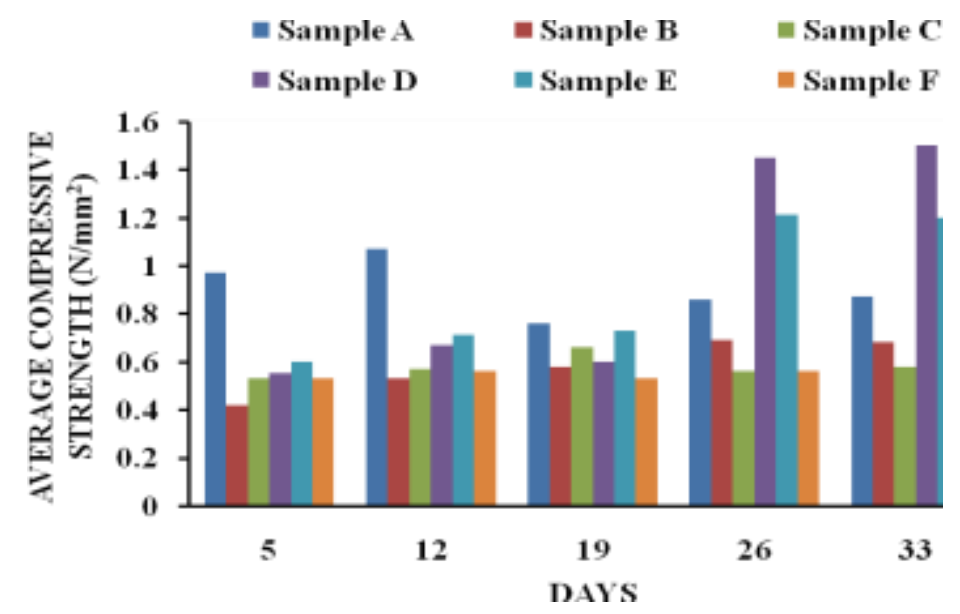

Figure 4.1: A Histogram of Average compressive strength of clay brick samples against curing days

Figure 4.1 represent the average compressive strength of clay bricks in partial replacement of cement and Neem leaves ash at 5 , 12, 19, 26 and 33 curing days. From the Figure 4.1it was observed that the average compressive strength of the bricks at 10\% Neem leaves ash (20\% cement) attained the highest compressive strength of $1.50 \mathrm{~N} / \mathrm{mm}^{2}$ at 33 curing days while at $0 \%$ Neem leaves ash (30\% cement) of 5 days curing has the lowest average compressive of $0.42 \mathrm{~N} / \mathrm{mm}^{2}$. Therefore, 33 curing days has the highest computed compressive strength of $0.9 \mathrm{~N} / \mathrm{mm}^{2}$ but 5 curing days attained the lowest computed average compressive strength of $0.6 \mathrm{~N} / \mathrm{mm}^{2}$.

\subsubsection{Modulus Of Rapture}

These results were obtained for different samples after few curing days and were used to plot Figure 4.2.

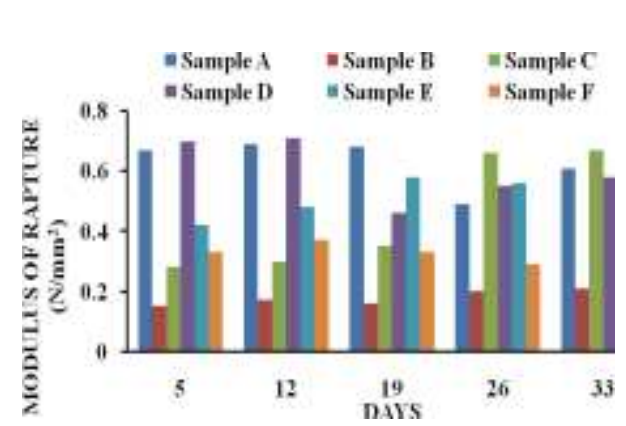

Figure 4.2: A Histogram of modulus of rapture of bricks samples against curing days

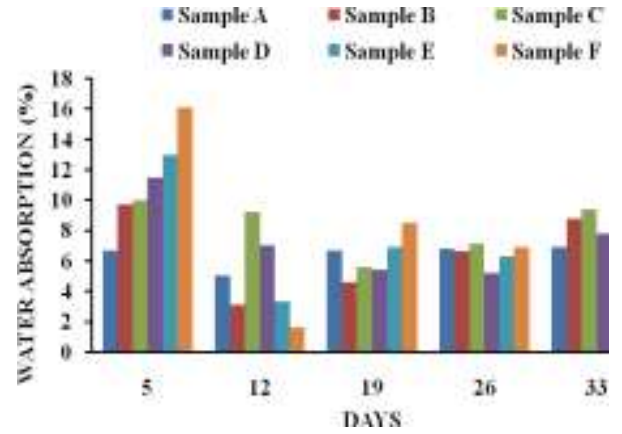

Figure4.3: A Histogram of water absorption of clays bricks samples against curing days

From the Figure 4.2 it was observed that the modulus of rapture of bricks at $10 \%$ Neem leaves ash (20\% cement) of 12 curing days attained the highest modulus of rapture of $0.71 \mathrm{~N} / \mathrm{mm}^{2}$. But at $5 \%$ Neem leaves ash ( $25 \%$ cement) of 12 curing days attained the lowest modulus of rapture of $0.15 \mathrm{~N} / \mathrm{mm}^{2}$. Therefore, it was observed that 33 days of curing attained the highest computed modulus of rapture of $0.5 \mathrm{~N} / \mathrm{mm}^{2}$ but 5 days and 19 days curing has the lowest computed modulus of $0.3 \mathrm{~N} / \mathrm{mm}^{2}$. 


\subsubsection{Water Absorption}

Figure 4.3 indicates the water absorptionm, from the Figure the water absorption increases by the quantity of Neem leaves ash with $20 \%$ addition ( $10 \%$ cement addition) at 5 curing days having the highest water absorption of $16.1 \%$ while bricks of same $20 \%$ addition of Neem leave ash (10\% of cement) record the lowest at 12 curing days of $1.6 \%$. Therefore, 5 days curing attained the highest computed water absorption of $11.2 \%$ while 12 days curing attained the lowest computed water absorption curing at $4.9 \%$.

\subsubsection{Initial Rate Of Absorption}

These results were obtained for different samples after few curing days and were used to plot Figure 4.4.

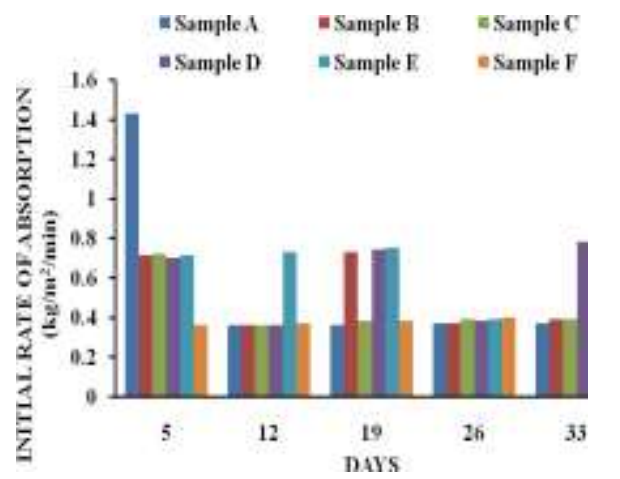

Figure 4.4: A Histogram of initial rate of absorption of clay bricks samples against curing days.

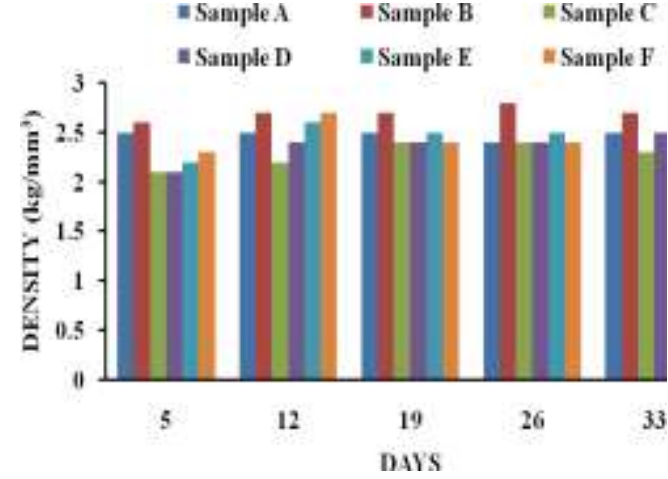

Figure 4.5: A Histogram of density of clay bricks againstcuring days.

Figure 4.4 illustrate the initial rate of absorption of clay bricks samples at 5, 12, 19, 26 and 33 curing days. From Figure 4.4 the initial rate of absorption gradually declined as the quantity of Neem leaves ash with $20 \%$ addition (10\% cement) at 5 curing days having the least initial rate of absorption of $0.36 \mathrm{~kg} / \mathrm{m}^{2} / \mathrm{min}$ while bricks with $5 \%$ Neem leaves ash (25\% cement) addition at the same 5 curing days attained the highest initial rate of absorption of $1.43 \mathrm{~kg} / \mathrm{m}^{2} / \mathrm{min}$. Therefore, it indicate the 5 days curing has the highest computed initial rate of water absorption of $0.77 \mathrm{~kg} / \mathrm{m}^{2} / \mathrm{min}$ while 26 days has the lowest computed initial rate of absorption of $0.38 \mathrm{~kg} / \mathrm{m}^{2} / \mathrm{min}$.

\subsubsection{Density}

These results were obtained for different samples after few curing days and were used to plot Figure 4.5. Figure 4.5 illustrate the density as a function of curing days which is of clay bricks in partial replacement of cement and Neem leaves ash at 5, 12, 19, 26, 33 curing days. It was observed the density of bricks samples at $0 \%$ Neem leaves ash (30\% Cement) of 26 curing days attained the highest density of $2.8 \mathrm{~kg} / \mathrm{mm}^{3}$. But the density of the bricks at $5 \%$ and $10 \%$ Neem leaves of 5 days has the lowest density of 2.1 $\mathrm{kg} / \mathrm{mm}^{3}$.

\subsubsection{Thermal Conductivity}

The thermal conductivity analysis was performed on test clay bricks mixed with cement and percentage of Neem leaves ash by weight at different thickness $2 \mathrm{~cm}$.

Figure 4.6 illustrates the thermal conductivity for $2 \mathrm{~cm}$ thicknessof the samples after 5 days of curing. From Figure 4.6 the thermal conductivityfor $2 \mathrm{~cm}$ thickness shows that sample D at 8 minutes attained the highest thermal conductivity of $118.97 \mathrm{w} / \mathrm{m} / \mathrm{k}$ while sample A at 2 minutes is the lowest of $16.49 \mathrm{w} / \mathrm{m} / \mathrm{k}$. 
International Journal of Advances in Scientific Research and Engineering (ijasre), Vol 7 (5), May-2021

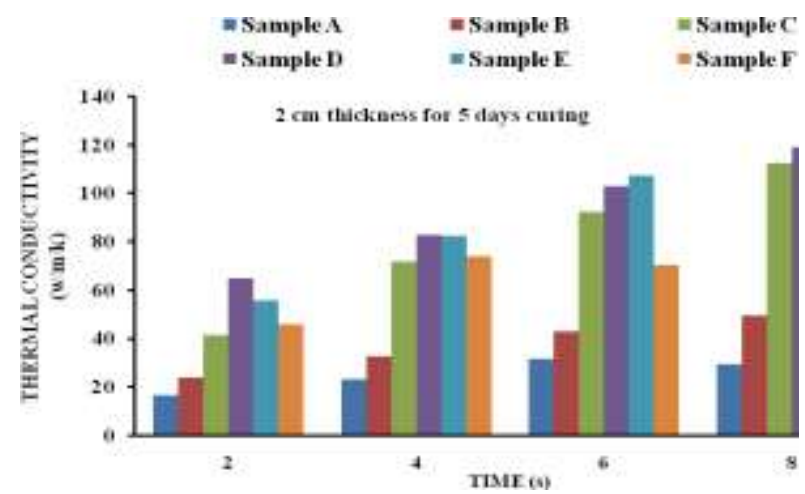

Figure 4.6: A Histogram showing the thermal conductivity of $2 \mathrm{~cm}$ thickness for 5 days curing against time

Figure 4.6.1. Illustrate the thermal conductivity for 2 cmthickness respectively of the samples after 12 curing days. From Figure 4.6.1 the thermal conductivity for $2 \mathrm{~cm}$ thickness show that sample $\mathrm{C}$ at 4 minutes attained the highest thermal conductivity of $125.07 \mathrm{w} / \mathrm{m} / \mathrm{k}$ while sample D at 2 minutes is the lowest of $44.48 \mathrm{w} / \mathrm{m} / \mathrm{k}$.

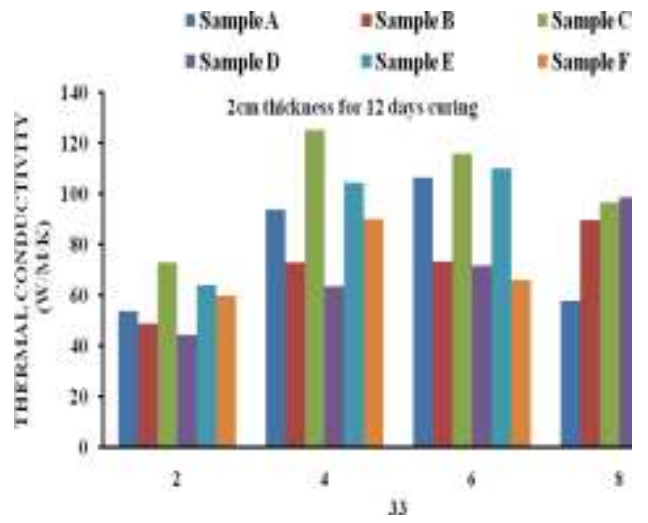

Figure 4.6.1: A Histogram showing the thermal conductivity of $2 \mathrm{~cm}$ thickness of the samples after 12 days against time.

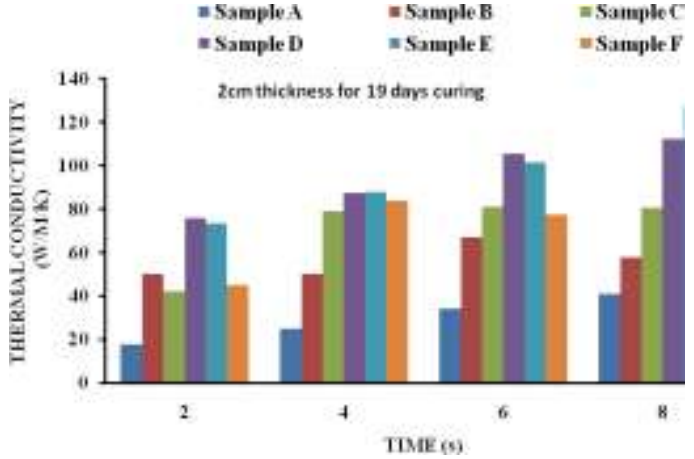

Figure 4.6.2: A Histogram showing the thermal conductivity of $2 \mathrm{~cm}$ thickness of the samples after 19 days against time.

Figure 4.6.2 illustrate the thermal conductivity for 2 cmthickness respectively of the samples after 19 days of hardening by shading process. From Figure 4.6.2 the thermal conductivity for $2 \mathrm{~cm}$ thickness shows that sample $\mathrm{E}$ at 8 minutes attained the highest thermal conductivity of $127.74 \mathrm{w} / \mathrm{m} / \mathrm{k}$ while sample A at 2 minutes is the lowest thermal conductivity of $17.65 \mathrm{w} / \mathrm{m} / \mathrm{k}$.

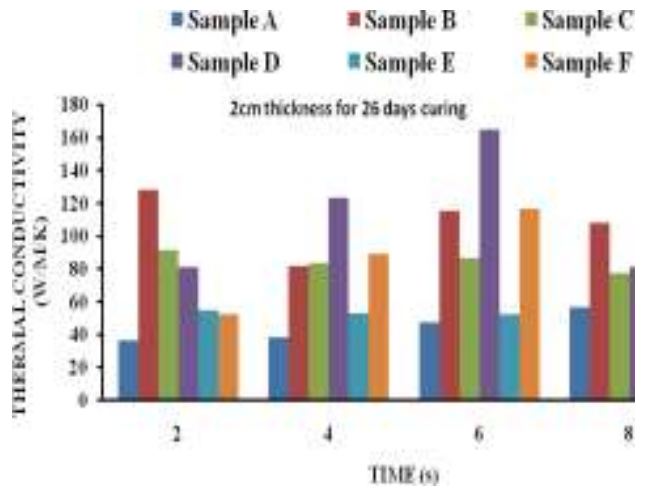

Figure 4.6.3: A Histogram showing the thermal conductivity of $2 \mathrm{~cm}$ thickness of the samples after 26 days against time.

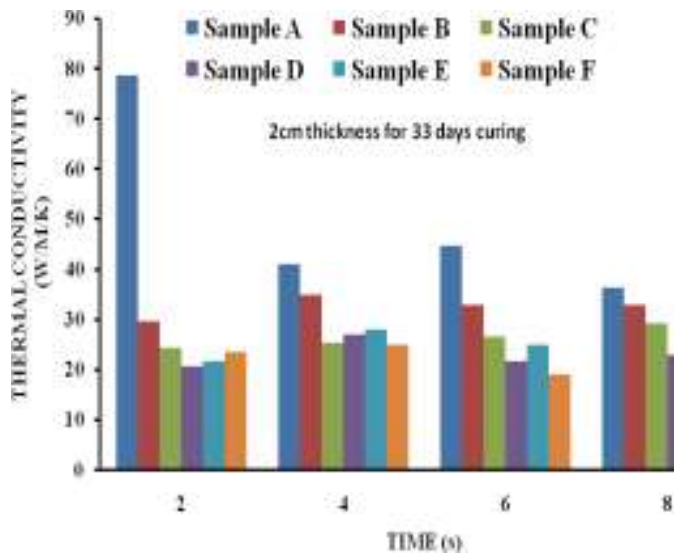

Figure 4.6.4: A Histogram showing the thermal conductivity of $2 \mathrm{~cm}$ thickness of the samples after 33 days against time

Figure 4.6.3 shows the thermal conductivity for 2 cmthickness respectively of the samples after 26 days of hardening by shading process. From Figure 4.6.9 the thermal conductivity for $2 \mathrm{~cm}$ thickness shows that sample D at 6 minutes is the highest thermal conductivity of $164.45 \mathrm{w} / \mathrm{m} / \mathrm{k}$ while sample A at 2 minutes is the lowest thermal conductivity of $36.73 \mathrm{w} / \mathrm{m} / \mathrm{k}$.. 
Figure 4.6.4 shows the thermal conductivity for $2 \mathrm{~cm}$ thickness of the samples after 33 days of curing. From Figure 4.6 .4 the thermal conductivity for $2 \mathrm{~cm}$ thickness shows that sample A at 2 minutes attained the highest thermal conductivity of $74.52 \mathrm{w} / \mathrm{m} / \mathrm{k}$ while sample $\mathrm{F}$ at 6 minutes attained the lowest of $18.87 \mathrm{w} / \mathrm{m} / \mathrm{k}$.

Therefore, for thermal conductivity, the sample A at 2 minutes for 5 days curing attained the lowest thermal conductivity of $16.49 \mathrm{w} / \mathrm{m} / \mathrm{k}$ while sample D at 6 minute for 26 days curing attained the highest thermal conductivity of $164.45 \mathrm{w} / \mathrm{m} / \mathrm{k}$.

\section{CONCULSION}

Based on the test result it can be concluded that Neem leaves ash can be used as partial replacements of cement in clay bricks as it possess the reliability and workability in improving both the physical and thermal properties of clay bricks.

\section{REFERENCES}

1. Ahmad, A. Z., Johari, I., Said, S., Ramadhansyah, P. J., \& Abubakar, B. H. (in press). Chemical and Physical Proporties of Fired clay bricks at Different Types of Rice Husk Ash. 2011 International Conference on Enviromental Science and Engineering.

2. Agarwal, A., (1981). Mud The potential of Earth-Based Materials for 3rd World Housing. London: Earhsran Publishers.

3. Alexandra R.R., and Alan W. R.. (2013). Rocks, Clays, Water and Salts: Highly Durable, Infinitely Rechargeable, Eminently Controllable Thermal Batteries for Buildings, Geosciences, 3, 63-101.

4. Burrough, S. (2002b). Development projects. In Earth builder-an environmentally sustainable building technology publication. Sydney. Australia.

5. Doat, P., Hays, A., Houben, H., Matuk, S., and Vitoux, F. (1991). Building with Earth. New Delhi: The Mid Village society,

6. Grimm, C. T. (1996). Clay Brick Masonry Weight Variation. Journal of Architectural Engineering, Vol. 2, No. 4, pp. 135-137

7. Hendry, A.W. (2001). Masonry walls: materials and construction. Construction and building Materials, 15. 323-330. Elsevier.

8. Hendry, A.W., Sinha, B.P., and Davies S.R. (1981). An introduction to load bearing brickwork design. U.K.: Ellis Horwood Limited.

9. Hisham, H.A., (2016) "Properties of Fire clay bricks mixed with waste glass" (M.S.c, The Islamic University-Gaza,

10. Howe, C. (1992). Sustainable earth building for the ecocity. Proceedings of conference on urban ecology. April 1992,Sydney: Australia.

11. Ifeka, N. U., (2004). Nigeria: Building better lives bricks by brick Ford Foundation International Fellowship Programme Alumni Report. New York: May 28, 2004.

12. Kenedy, J. f. (2002). An overview of building techniques. Natural building colloquium. Southwest, New Mexico. 
International Journal of Advances in Scientific Research and Engineering (ijasre), Vol 7 (5), May-2021

13. Khalaf, F. M. and Devenny, A. S. (2002). "New Tests for Porosity and Water absorption of Fired Clay Bricks." Journal of Material in Civil Engineering.

14. Kung, J. H., (1987). Frost-Durability Study on Canadian Clay Bricks. III. Characterization of raw materials and burnt clay bricks. Durability of Building Materials, 5, 125-143.

15. Lenczner, D., (1972). Elements of Load-bearing Brickwork. Oxford, New York,Toronto, Sydney, Braunschweig.: Pergamon Press,

16. Maini, S. (2002). Earth architecture for sustainable habitat and compressed stabilized earth block technology. India: Auroville Earth Institute, Auroville Building Centre.

17. Mohammed, A.A., and Shakir A.A. (2013). Manufacturing of bricks in the past, in the present and in the future: A state of the Art Review. International Journal of Advances in Applied Science, 2, 145-156.

18. Moris, J., andBooysen, Q. (2005). Earth construction in Africa Proceedings: Strategies for a sustainable Built Environment. Pretoria: 23-25August.Organization: Paris, UNESCO.

19. Nurudeen M.M., Ocholi A., Abubakar I., andEjeh S.P. (2014). Effect of Neem Seed Husk Ash on Concrete Strength Properties. African Jounals Online, 33, 2..

20. Nwachukwu, N. A. (2010). Optimization of rice-husk-ash and straw as stabilising agents for earth materials (mud) in earth building construction. Unpublished Ph.D Thesis, Department of Vocational Teacher Education; University of Nigeria, Nsukka.

21. Sahil S. (1971). Structural Masonary. Michigan: Prentice Hall

22. Surej, R. K., Fazio, P. and Feldman, D. (1998). Comparative Study of Durability Indices for Clay Bricks. Journal of Architectural Engineering. 5, 2 2- 32

23. Torraca G. (1988). Porous Building Materials. Material Science for Architectural Conservation, $3^{\text {rd }}$ Edition. Rome, Italy.

24. Zainab. A.A. (2005). Properties of Malaysian Fired Clay Bricks and Their Evaluation with International Masonry Specifications - A Case Study. (M.sc., University of Technology, Malaysia, 2005).

Corresponding Author's Email Address: bshamza2024@gmail.com 